\title{
Structure-order relationships in liquid crystalline polyesters
}

\author{
Robert W. Lenz \\ Chemical Engineering Department, University of Massachusetts, \\ Amherst, Mass. 01003 USA
}

\begin{abstract}
Several series of polyesters containing mesogenic groups based upon aromatic ester triads and polymethylene flexible spacers have been prepared and characterized for their liquid crystalline properties in the melt. The relationships between repeating unit structure and the type of mesophases formed, as well as their transition temperatures and other thermodynamic properties, are discussed for both these main chain, liquid crystalline polymers and their model compounds. Particular consideration is given to the effects of small variations in the triad ester sequences, substituent effects and aspect ratio of the mesogenic group on thermotropic properties.
\end{abstract}

\section{INTRODUCTION}

It is remarkable that the existence of liquid crystalline order in the melt state of polymers was first described in the patent literature only in 1974 (ref. 1) and in polymer journals only in 1975 (ref. 2) and independently in 1976 (ref. 3). Hence, this field of study is scarcely more than ten years old. Indeed, such type of order was so unexpected that numerous patents on aromatic polyesters, which are known today to form thermotropic melts, issued in the 1960s and early 1970s make no mention of this property (ref. 4). With such a recent history, therefore, it is not so surprising that our understanding of this type of non-crystalline order is so meager and so premature compared to our knowledge of crystalline order in polymers.

It is also likely that for many of the aromatic polyesters studied in the 1960s and early 1970s, their liquid crystalline properties were either overlooked or given very little consideration because their melting points were so high, in many cases well above $400^{\circ} \mathrm{C}$. Such high melting points, which are characteristic of polymers containing sequences of linear, rigid aromatic ester units, limited both the applications of these polymers and their experimental study, as well as the characterization of their properties. Hence, now that the possible utility of thermotropic behavior in polymers has been recognized, considerable attention is being devoted to reducing their melting points, and as a result, a wide variety of types of polymers with accessible thermotropic states are now available for study (ref. 5).

The principal approaches to this end have been through the use of one or more of the following types of structural modifications: (1) substituents on the mesogenic units, I; (2) flexible spacers separating the mesogenic units, II; (3) copolymerization of two different types of mesogenic units, III; and (4) copolymerization of a mesogenic with a nonmesogenic unit, IV (ref. 6); as illustrated schematically below:

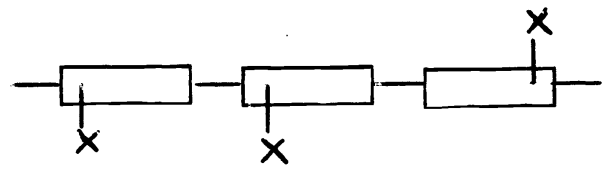

$I$
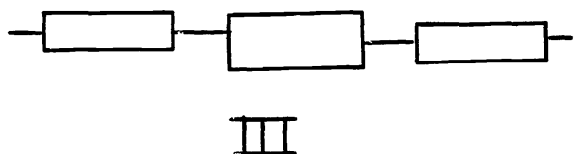

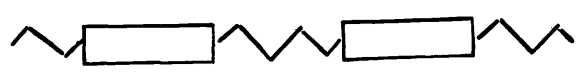

II




These types of structural modifications have generated many important observations on structure-property relationships in thermotropic polymers, for which there is as yet very little basis for rigorous understanding or theoretical explanation. We have encountered and addressed a number of these relationships in our studies on the preparation of many new types of polymers and copolymers of types I through IV, including the effects of changes in: (1) mesogenic group size, shape and structure; (2) polar and steric substituents on the mesogen; (3) type and length of the flexible spacer; and (4) type and amount of non-mesogenic comonomer units. In each the principal properties studied were the type and the thermal transitions of the liquid crystalline phase formed (ref. 7). In many cases, closely analogous model compounds were also prepared for comparison of their properties with those of the polymers, but quite often parallel structure-property relationships were not necessarily observed, as discussed below for several comparisons of this type.

\section{TYPE OF MESOPHASE}

Several different series of polymers of type II have been prepared in which systematic changes in the structure of the mesogenic group were made while the type and length of the flexible spacer were kept the same. When the spacer was a polymethylene group, the resulting polymers generally formed a nematic phase on melting, with one notable exception as shown in Table 1 .

TABLE 1. Polymers with triad ester mesogens

\begin{tabular}{|c|c|c|c|c|c|}
\hline \multirow[t]{2}{*}{ Polymer } & \multirow[t]{2}{*}{ Repeating Unit } & \multicolumn{2}{|c|}{ Transition Temp.,${ }^{\circ} \mathrm{C}^{\mathrm{a}}$} & \multirow[t]{2}{*}{ Mesophase } & \multirow[t]{2}{*}{ Ref. } \\
\hline & & $\mathrm{T}_{\mathrm{m}}$ & $\mathrm{T}_{\mathrm{I}}$ & & \\
\hline A & CO & 231 & 267 & Nematic & 8 \\
\hline B & & 236 & 305 & Nematic & 9,10 \\
\hline C & & 265 & 321 & Nematic & 10,11 \\
\hline D & 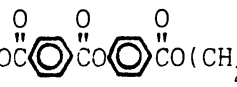 & 220 & 267 & Smectic & 12 \\
\hline
\end{tabular}

a As determined by DSC.

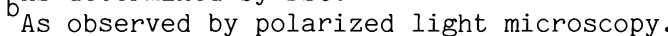

Only Polymer D in Table 1 formed the more highly ordered smectic phase, but somewhat surprisingly considering the normal behavior of many low molecular weight smectic liquid crystals, at a higher temperature this phase is transformed directly into an isotropic phase rather than forming an intermediate nematic phase first, even though its isotropization, or clearing, temperature was still relatively low. Furthermore, a model compound with the same mesogenic group, Model $\mathrm{H}$, was recently prepared by us and found to undergo the more usual series of transitions for low molecular weight liquid crystals from crystalline (C), to smectic (S), to nematic (N), to isotropic (I) as shown in Table 6, Model Compound $\mathrm{H}$.

Polymer B in Table 1 had previously been reported by Strzelecki and van Luyen (ref. 9) to form both smectic and nematic phases and also to have a smectic-to-smectic transition, with the following transitions: $\mathrm{T} / 105^{\circ}, \mathrm{T}_{\mathrm{S} / \mathrm{S}} 215^{\circ}, \mathrm{T}_{\mathrm{S} / \mathrm{N}} 225^{\circ}$, and $\mathrm{T}_{\mathrm{T}} 270^{\circ} \mathrm{C}$, respectively. We were unable to observe the lower temperature Smectic forms in our sample of Polymer $\mathrm{B}$, and the $\mathrm{T}$ transition we observed was much higher, as shown in Table 1 . The difference in $\mathrm{T}_{\mathrm{T}}$ could be a molecular weight effect, but it is doubtful that the difference in type of mesophase formed could be too. 
On the other hand, we have recently prepared a polymer, Polymer J, with the same mesogenic group as Polymer B, but with a longer spacer than the members of the series which were studied by Strzelecki and van Luyen, the dodecamethylene spacer (ref. 13). This polymer did indeed form both smectic and nematic phases with transitions very similar to those reported for the polymer with the decamethylene spacer (ref. 9), as shown in Table 5, Polymer J.

It should be noted, however, that two of the closely related model compounds, of the general type Model B, which contain the same mesogenic group with terminal hexyl and decyl ether groups, were reported by Dewar and Goldbert (ref. 14) to melt directly into a nematic phase with the following transition temperatures:

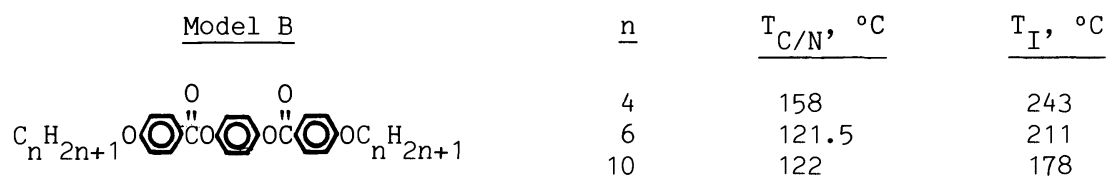

Included also in this tabulation are the transition temperatures of the model compound containing the butyl ether group, which we recently prepared.

It would seem to be unusual, and it does not meet with our general experience, that a model compound should form a liquid crystalline phase of lower order than the corresponding polymer, so these polymers and compounds are worthy of more intensive study.

Equally difficult to understand is the observed variation in the type of liquid crystalline phase formed on melting within a series of polymers with a given mesogenic group but in which small changes in the length of the flexible spacer are made, as has been reported for several different types of thermotropic polyesters and summarized in Table 2. The odd-even effects on thermotropic properties, particularly for the variation in isotropization transition temperatures, $\mathrm{T}_{\mathrm{I}}$, and in the thermodynamic parameters, which have often been observed, are also apparent in the relationship between mesophase type and spacer length in the polymers in Table 2. While attempts have been made to rationalize the odd-even effects on $\mathrm{T}_{\mathrm{I}}$ and on the enthalpy and entropy of clearing, $\Delta \mathrm{H}_{\mathrm{I}}$ and $\Delta \mathrm{S}_{\mathrm{I}}$ (refs. 16, $17,18)$, no such consideration has been given to this effect on the type of phase formed.

TABLE 2. Variation in mesophase type with spacer length

\begin{tabular}{|c|c|c|c|c|}
\hline Polymer & Repeating Unit & $\mathrm{n}$ & Phase Formed & Reference \\
\hline D &  & $\begin{array}{c}3 \\
4 \\
5 \\
6 \\
7-12\end{array}$ & $\begin{array}{l}\mathrm{S} \\
\mathrm{N} \\
\mathrm{S} \\
\mathrm{N} \\
\mathrm{S}\end{array}$ & 12 \\
\hline B & $\stackrel{0}{\mathrm{C} 0} \mathrm{O}$ & $\begin{array}{l}2-5 \\
6-11 \\
10 \\
12\end{array}$ & $\begin{array}{l}\mathrm{N} \\
\mathrm{S} \\
\mathrm{N} \\
\mathrm{S}\end{array}$ & $\begin{array}{r}9 \\
9 \\
10 \\
13\end{array}$ \\
\hline $\mathrm{E}$ & 2) (O) $-\stackrel{0}{\prime \prime}\left(\mathrm{CH}_{2}\right)$ & $\begin{array}{c}5,7 \\
6,8,10,12\end{array}$ & $\begin{array}{l}\mathrm{N} \\
\mathrm{S}\end{array}$ & 15 \\
\hline
\end{tabular}

\section{THERMAL STABILITY OF MESOPHASE}

A measure often used of the relative stabilities of the mesophases formed, within a series of closely related thermotropic compounds and polymers, is their isotropization temperatures. However, the theoretical relationship between the stability of the liquid crystalline phase and the structure of the polymer is much better developed for lyotropic behavior than for thermotropic behavior in terms of the molecular features responsible for liquid crystallinity, which are (1) asymmetry of molecular shape and (2) anisotropy of molecular forces (refs. 19, 20). The former is given in terms of the length-to-width or axial ratio of the mesogen, which is a basic parameter for predicting the isotropicanisotropic phase behavior of lyotropic systems.

This parameter, through its effect on the persistence length, also controls the liquid crystalline behavior of thermotropic systems. Hence, any structural changes in the 
mesogenic group of a thermotropic homopolymer, which cause variations in the axial ratio, should result in consistent variations in the liquid crystalline properties of the polymer, particularly in the values of $\mathrm{T}_{\mathrm{I}}, \Delta \mathrm{H}_{\mathrm{T}}$ and $\Delta \mathrm{S}_{\mathrm{I}}$. The effects of such changes have been studied for several series of polymers and their model compounds in our investigations of structure-order relationships.

The relative contributions of anisotropic molecular forces to these thermodynamic properties have also been considered in our investigations through the use of polar or polarizable lateral substituents in the mesogenic groups. Attractive dipolar forces between substituents on neighboring units increase the interchain interaction energy, and this parameter combined with the persistence length, determines $\mathrm{T}_{\mathrm{I}}$ and the order parameter within the liquid crystal phase (ref. 21). The order parameter and the interchain attractive forces, in turn, are the principal factors which determine $\Delta \mathrm{H}_{\mathrm{I}}$, while the steric interactions, or packing arrangements, along with the conformational ordering of the flexible spacers, determine $\Delta S_{I}$ (ref. 22).

\section{Substituent effects}

The effect of lateral substituents on mesophase stability has been little studied for polymers (refs. 2, 23, 24), but has been quite extensively so for low molecular weight liquid crystals (ref. 25). In one of our earlier studies, we found that placing a single substituent, $\mathrm{R}$, on the central hydroquinone ring of Polymer $\mathrm{B}$ in Table 1 caused $\mathrm{T}_{\mathrm{I}}$ to decrease in a regular manner with increasing size of the substituent when the substituent, $\mathrm{R}$, was either $\mathrm{H}, \mathrm{CH}_{3}, \mathrm{Cl}$ or $\mathrm{Br}$ :

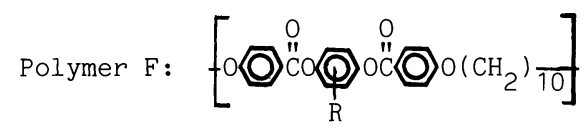

This result was taken as an indication that the predominant effect of the substituents was steric repulsion, which increased the separation of neighboring mesogenic units and, thereby, that of the long axes of polymer chains, in the same manner as has been reported for low molecular weight liquid crystals. All of the polymers in this series were nematic.

We also described, in a previous report, the preparation and properties of a series of monosubstituted derivatives of Polymer A containing $n$-alkyl substituents on the central hydroquinone ring of the mesogenic group which varied in length from the methyl to the decyl group (ref. 26). The polymers in this series, Polymer G, were all nematic when the substituent was increased in size from methyl to hexyl, but the octyl and decyl substituted polymers did not form a liquid crystalline mesophase. For the lower members of the series, the $\mathrm{T}_{\mathrm{I}}$ values again decreased in a uniform manner with increasing alkyl group size.

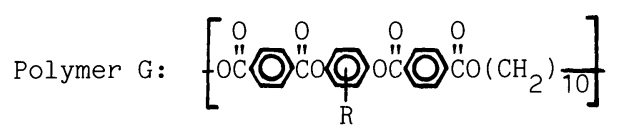

Polarity effects were also studied for Polymer $G$ in which the central hydroquinone ring contained either an alkyl group or a group from the series: $\mathrm{Br}, \mathrm{NO}_{2}, \mathrm{CN}$ and $\mathrm{OCH}_{3}$ groups (ref. 24). The molecular diameters of the hydroquinone rings containing the $\mathrm{CH}_{3}, \mathrm{Br}, \mathrm{NO}_{2}$ and $\mathrm{CN}$ groups are not too much different $(7.8,8.1,8.3$ and $8.3 \AA$, respectively), while the $\mathrm{OCH}_{3}$ and $\mathrm{C}_{2} \mathrm{H}_{5}$ derivatives are considerably broader (8.9 and $9.0 \AA$, respectively). Nevertheless, the $\mathrm{T}_{\mathrm{I}}$ values for the $\mathrm{CN}$ containing polymer $\left(219^{\circ} \mathrm{C}\right)$ was much higher than those of the $\mathrm{CH}_{3}, \mathrm{Br}$ and $\mathrm{NO}_{2}$ polymers, all of which were in the range of $190-194^{\circ} \mathrm{C}$. The $\mathrm{OCH}_{3}$ polymer was monotropic, and from studies on a series of copolymers its $\mathrm{T}_{\mathrm{I}}$ value was estimated to be close to $150^{\circ} \mathrm{C}$ (ref. 27 ), which is considerably below those of all of the others.

These data strongly point to the existence of conflicting steric and polar effects on the thermal stabilities, as indicated by the $\mathrm{T}_{I}$ values, of the nematic mesophases formed by the polymers in this series. The high polarity of the CN group apparently stabilizes the mesophase, as was also observed for low molecular liquid crystals based on substituted aromatic esters (ref. 28), but the $\mathrm{NO}_{2}$ group, which is also highly polar, does not do so in comparison with the polymers containing the non-polar $\mathrm{CH}_{3}$ and the low polarity $\mathrm{Br}$ groups. The presence of the large $\mathrm{OCH}_{3}$ and $\mathrm{C}_{2} \mathrm{H}_{5}\left(\mathrm{~T}_{\mathrm{I}}\right.$ of $\left.127^{\circ} \mathrm{C}\right)$ groups, as would be expected, considerably decrease $\mathrm{T}_{\mathrm{I}}$ of nematic phases of their polymers (ref. 25). For small molecule liquid crystals, the decrease in $\mathrm{T}_{\mathrm{I}}$ with increasing substituent size has been attributed principally to a reduction in $\Delta S_{I}$ caused by a reduction in the mobility of the molecules resulting from an interlocking of the substituents (ref. 29).

No quantitative relationships have as yet been developed to relate the relative contributions of each of these factors, steric and polar, to determining $\mathrm{T}_{\mathrm{I}}$. However, even for well-defined low molecular weight liquid crystalline compounds, quantitative relationships for these factors have not been established, although it is generally accepted that steric 
factors generally play the predominant role in controlling the thermal stability of mesophases of such compounds (ref. 25), and considerable data can be found in the literature on the thermotropic properties of aromatic ester liquid crystals including a closely related series of hydroquinone di-p-methoxybenzoates with different substituents on the central phenyl ring (ref. 29).

\section{Thermodynamic parameters}

While the contributions of increasing steric interactions to decreasing $\mathrm{T}_{\mathrm{I}}$ values within a series of polymers with a common mesogenic group appear to follow a regular pattern, the effects on $\Delta \mathrm{H}_{\mathrm{I}}$ and $\Delta \mathrm{S}_{\mathrm{I}}$ often do not. We have observed this type of anomaly in a series of alkyl-substituted derivatives of Polymer $\mathrm{F}$ and their related model compounds, Model $\mathrm{F}$, both of which contained the same basic mesogenic group as that of Polymer B in Table 1, as follows:

$$
\text { Model Compound F: } \mathrm{C}_{4} \mathrm{H}_{9} \mathrm{O}
$$

The thermodynamic properties for these polymers and model compounds, all of which form nematic mesophases, are listed in Table 3 (ref. 30). For both the model compounds and the polymers, the $\mathrm{T}_{\mathrm{T}}$ values decrease in a regular manner with increasing substituent size, but the values of $\Delta \mathrm{H}_{\mathrm{T}}$ and $\Delta \mathrm{S}_{\mathrm{I}}$ pass through maxima for both. It is difficult to rationalize these conflicting effects especially in comparison with the previously reported behavior of steric effects on model compounds (ref. 29).

TABLE 3. Thermodynamic parameters for Polymer $B$ and its derivatives, Polymer $F$ and Model Compound $\mathrm{F}$

\begin{tabular}{|c|c|c|c|c|c|c|}
\hline \multirow[t]{2}{*}{ Substituent, R } & \multicolumn{3}{|c|}{ Model Compound ${ }^{a}$} & \multicolumn{3}{|c|}{ Polymer ${ }^{a}$} \\
\hline & $\mathrm{T}_{\mathrm{I}},{ }^{\circ} \mathrm{C}$ & $\Delta \mathrm{H}_{\mathrm{I}}$ & $\Delta \mathrm{S}_{\mathrm{I}}$ & $\mathrm{T}_{\mathrm{I}},{ }^{\circ} \mathrm{C}$ & $\Delta \mathrm{H}_{\mathrm{I}}$ & $\Delta S_{I}$ \\
\hline $\mathrm{H}$ & 245 & 0.77 & 1.5 & 305 & 1.1 & 1.9 \\
\hline $\mathrm{CH}_{3}$ & 206 & 0.77 & 1.6 & 280 & 1.8 & 3.3 \\
\hline $\mathrm{C}_{2} \mathrm{H}_{5}$ & 158 & 0.59 & 1.4 & 234 & 1.6 & 3.2 \\
\hline
\end{tabular}

anits: $\Delta \mathrm{H}_{\mathrm{I}}$ in $\mathrm{Kcal} / \mathrm{mole}, \Delta \mathrm{S}_{\mathrm{I}}$ in cal/mole $\mathrm{K}$.

In an attempt to more clearly separate steric and polar effects, we have also recently prepared another, more extensive series of derivatives of Polymer $\mathrm{F}$ and Model Compound $\mathrm{F}$, again based upon the same basic mesogenic group as that of Polymer B in Table 1, but these contained a much larger lateral substituent, the p-substituted phenylsulfonyl group in which $\mathrm{R}$ is $\mathrm{x} \mathrm{O} \mathrm{SO}_{2}^{-}$, and $\mathrm{X}$ is either $\mathrm{H}, \mathrm{CH}_{3}, \mathrm{~F}, \mathrm{Cl}, \mathrm{Br}, \mathrm{I}, \mathrm{NO}_{2}$, or $\mathrm{OCH}_{3}(\mathrm{ref} .31)$. The thermodynamic properties of these model compounds and polymers are collected in Table 4.

TABLE 4. Thermodynamic Properties of Model Compounds and Polymers Based Upon Polymer B and Containing a Single p-Substituted Phenylsulfonyl Substituent

\begin{tabular}{|c|c|c|c|c|c|c|}
\hline \multirow{2}{*}{$\begin{array}{l}\text { p-Substituent, } \mathrm{x} \\
\text { in } \mathrm{x}\left(\mathrm{O} \mathrm{SO}_{2}^{-} \text {group, } \mathrm{R}\right.\end{array}$} & \multicolumn{3}{|c|}{ Model $\mathrm{F}^{\mathrm{a}}$} & \multicolumn{3}{|c|}{ Polymer $F^{a}$} \\
\hline & ${ }^{\mathrm{T}} \mathrm{I},{ }^{\circ} \mathrm{C}$ & $\Delta \mathrm{H}_{\mathrm{I}}$ & $\Delta \mathrm{S}_{\mathrm{I}}$ & ${ }^{\mathrm{T}} \mathrm{I},{ }^{\circ} \mathrm{C}$ & $\Delta \mathrm{H}_{\mathrm{I}}$ & $\Delta \mathrm{S}_{\mathrm{I}}$ \\
\hline $\mathrm{H}$ & 88 & 0.24 & 0.67 & 164 & 0.89 & 2.1 \\
\hline $\mathrm{CH}_{3}$ & 56 & 0.13 & 0.39 & 145 & 0.68 & 1.6 \\
\hline $\mathrm{F}$ & 119 & 0.22 & 0.57 & 156 & 0.85 & 2.0 \\
\hline $\mathrm{Cl}$ & 80 & 0.27 & 0.77 & 152 & 0.83 & 1.9 \\
\hline $\mathrm{Br}$ & 69 & 0.20 & 0.60 & 142 & 0.74 & 1.8 \\
\hline I & -- & -- & -- & 122 & 0.66 & 1.7 \\
\hline $\mathrm{NO}_{2}$ & -- & -- & -- & 146 & 0.61 & 1.5 \\
\hline $\mathrm{OCH}_{3}$ & -- & -- & -- & 122 & 0.48 & 1.2 \\
\hline
\end{tabular}

anits: $\Delta \mathrm{H}_{\mathrm{I}}$ in $\mathrm{Kcal} / \mathrm{mole}, \Delta \mathrm{S}_{\mathrm{I}}$ in cal/mole $\mathrm{K}$. 
The steric effect of the para-substituent on each of the thermodynamic properties is clearly evident, particularly for the halogen series, in both the model compounds and polymers, as shown by the relationships between $\mathrm{T}_{\mathrm{I}}, \Delta \mathrm{H}_{\mathrm{I}}$ and $\Delta \mathrm{S}_{\mathrm{I}}$ and the calculated radius of the substituted hydroquinone moiety in the polymers in Figures 1, 2 and 3, respectively. The steric effects were greater but not always parallel for the model compounds, particularly for the values of $\Delta \mathrm{H}_{\mathrm{I}}$ and $\Delta \mathrm{S}_{\mathrm{I}}$ in the halogen series.

For the polymers, the polar effect is more evident than in the previous series, discussed above, as seen by comparing the $\mathrm{T}_{\mathrm{I}}$ and $\Delta \mathrm{H}_{\mathrm{I}}$ values of the $\mathrm{NO}_{2}, \mathrm{Cl}$ and $\mathrm{Br}$ polymers with that of the $\mathrm{CH}_{3}$ polymer. The $\mathrm{OCH}_{3}$ group again has a strong detrimental influence, presumably steric, on $\mathrm{T}_{\mathrm{I}}$ and $\Delta \mathrm{H}_{\mathrm{I}}$. In all cases, however, both the energy of interaction as measured by $\Delta \mathrm{H}_{\mathrm{I}}$, and the orientational order, as measured by $\Delta \mathrm{S}_{\mathrm{I}}$, decreased with increasing size of the substituent.

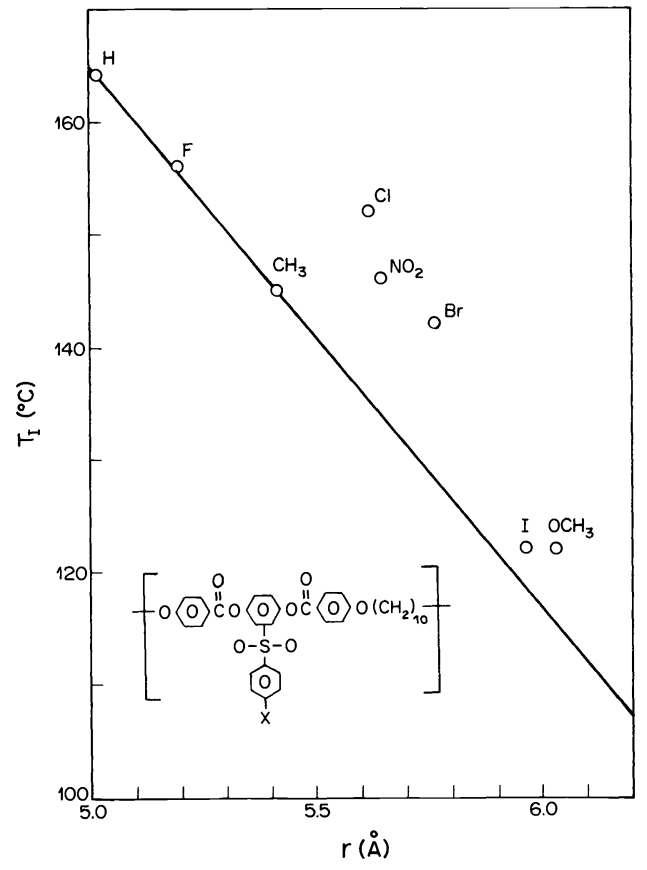

Fig. 1. Relationship between the isotropization temperature and the molecular radius of the substituted hydroquinone groups in the pheny1sulfonyl derivatives of Polymer B (see Table 4)
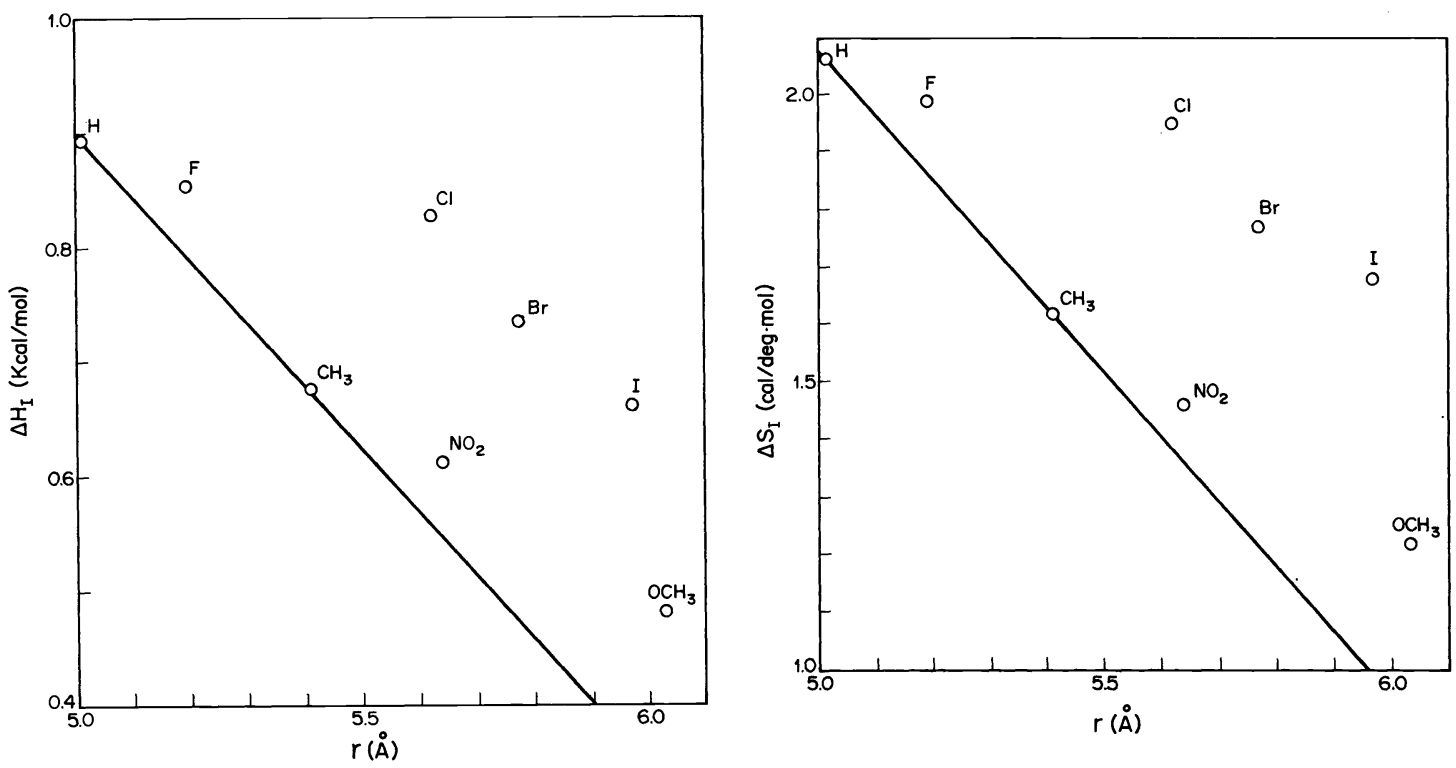

Fig. 2. Relationship between the enthalpy of isotropization and the molecular radius of the substituted hydroquinone groups in the phenylsulfonyl derivatives of Polymer $B$ (see Table 4)

Fig. 3. Relationship between the entropy of isotropization and the molecular radius of the substituted hydroquinone groups in the phenylsulfonyl derivatives of Polymer $B$ (see Table 4) 
TABLE 5. Comparison of Transition Temperatures of Two Pairs of Polymers Containing Either 1,4-Phenylene or 2,6-Naphthalene Rings in Their Mesogenic Groups

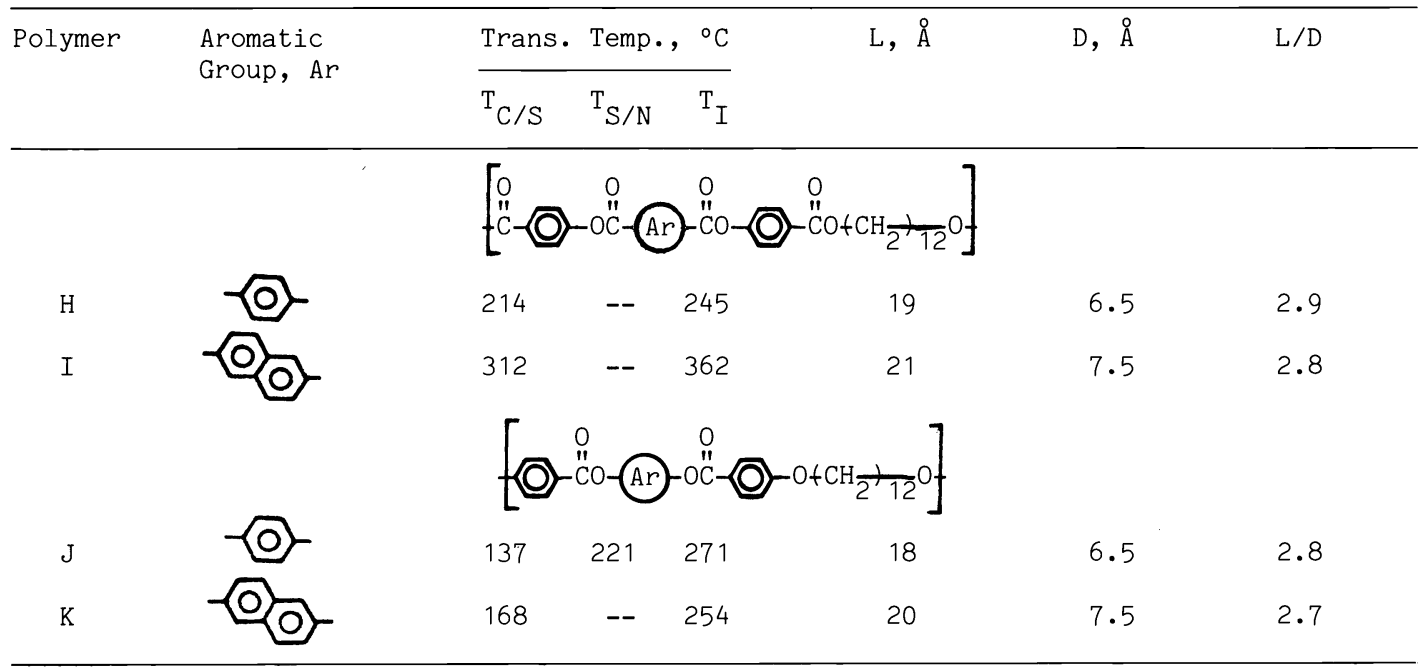

\section{Aspect ratio effects}

The use of monomers containing a 2,6-disubstituted naphthalene ring, in combination with those containing the 1,4-disubstituted phenylene ring to form mixed aromatic ester mesogenic groups has been found to be a particularly effective method of reducing the melting points of thermotropic copolymers of type III while retaining the ability to form a stable nematic phase (refs. 32, 33). Little information exists, however, of the effects of this type of unit, compared to the p-phenylene unit, on the thermal stability of the nematic phase because the isotropization temperatures of these all-aromatic polymers have always been too high to measure.

In an attempt to evaluate the role of the 2,6-naphthalene moiety, we recently prepared two new pairs of polymers and model compounds containing the same types of mesogenic groups as those in Polymers B and D of Table 1, but in each pair one had a central 2,6-naphthalene ring, Polymers $\mathrm{I}$ and $\mathrm{K}$, while the other had the 1,4-phenylene ring, Polymers $\mathrm{H}$ and $\mathrm{J}$, in the triad aromatic ester mesogenic unit, as shown in Table 5. All four of the polymers contained a dodecamethylene flexible spacer instead of the decamethylene spacer of Polymers $\mathrm{B}$ and $\mathrm{D}$ in Table 1. The structures and transition temperatures of these polymers and their model compounds are given in Tables 5 and 6 , respectively (ref. 13).

TABLE 6. Comparison of Transition Temperatures of Two Pairs of Model Compounds Containing Either 1,4-Phenylene or 2,6-Naphthalene Rings in Their Mesogenic Groups

Transition Temperature, ${ }^{\circ} \mathrm{C}$

$\mathrm{T}_{\mathrm{m}} \quad \mathrm{T}_{\mathrm{S} / \mathrm{N}} \quad \mathrm{T}_{\mathrm{I}}$<smiles>CCO[Ge](=O)c1ccc(OC(=O)c2ccc(OC(=O)c3ccc([Ge](=O)OCC)cc3)cc2)cc1</smiles>

$\mathrm{H}$

I

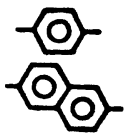

$\mathrm{BuO}-\mathrm{O}-\stackrel{0}{\mathrm{C}} \mathrm{C}-\mathrm{Ar}-\stackrel{0}{\prime \prime}-\mathrm{O}-\mathrm{OBu}$

$\begin{array}{lll}196 & 205 & 238 \\ 221 & - & 295\end{array}$


The 2,6-naphthalene and 1,4-phenylene rings have essentially the same aspect ratios, as indicated by the L/D values in Table 5, but, their liquid crystalline properties are considerably different, and for both pairs the model compounds again show different properties than do the polymers.

The predominant effect of the presence of the 2,6-naphthalene ring is to greatly increase both $\mathrm{T}_{\mathrm{m}}$ and the mesophase stability as is clearly seen in comparing the $\mathrm{T}_{\mathrm{I}}$ values of Polymers $\mathrm{H}$ and $\mathrm{I}$, both of which form smectic phases, and Model Compounds $\mathrm{H}$ and $\mathrm{I}$ even though $\mathrm{H}$ melts first to a smectic phase then forms a nematic phase before $\mathrm{T}_{\mathrm{I}}$ is attained. Similarly, for Model Compounds $\mathrm{J}$ and $\mathrm{K}$, both of which form only nematic phases, the $\mathrm{T}_{\mathrm{I}}$ value for the naphthalene containing compound is much higher.

For Polymers $\mathrm{J}$ and $\mathrm{K}$ of Table 5, the comparison is less straightforward because the former forms both smectic and nematic phases while the latter forms only a smectic phase. In this case, the appropriate comparison is in the relative thermal stabilities of the two smectic phases, for which the naphthalene containing compound, $\mathrm{K}$, is again higher.

The ability of the naphthalene ring to impart a much increased thermal stability to a liquid crystalline mesophase, without affecting the type of mesophase formed, may be because of, rather than in spite of, its larger diameter. That is, the broader and more polarizable naphthalene rings may be capable of both stronger dipolar interactions and greater steric interlocking effects than the 1,4-phenylene rings. However, the transition temperatures in Tables 5 and 6 were determined by visual observations of samples on a polarizing microscope, and the thermodynamic parameters for these polymers and model compounds are presently being evaluated by differential scanning calorimetry.

\section{ACKNOWLEDGEMENT}

I am grateful to the Office of Naval Research and the National Science Foundation, for the support of my research program on liquid crystalline polymers, and to my many coworkers who have carried out the experimental studies on which this report is based.

\section{REFERENCES}

1. J. J. Kleinschuster, T. C. Pletcher and J. R. Schaefgen, Belg. Pat. 828,935 (1974).

2. A. Roviello and A. Sirigu, J. Polym. Sci., Polym. Letters Ed., 13, 455 (1975).

3. W. J. Jackson and H. F. Kuhfuss, J. Polym. Sci., Polym. Chem. Ed., 14, 2093 (1976).

4. M. G. Dobb and J. E. McIntyre, Adv. Polym. Sci., $60 / 61,61$ (1984).

5. C. K. Ober, J.-I. Jin, Q.-F. Zhou and R. W. Lenz, Adv. Polym. Sci., 59, 103 (1984).

6. B. P. Griffin and M. K. Cox, Brit. Polym. J., 12, $147(1980)$.

7. R. W. Lenz, Polym. J., 17, 105(1985).

8. Q.-F. Zhou and R. W. Lenz, J. Polym. Sci., Polym. Chem. Ed., 21, 3313 (1983).

9. L. Strzelecki and D. van Luyen, European Polym. J., 16, 299 (1980).

10. S. Antoun, R. W. Lenz and J.-I. Jin, J. Polym. Sci., Polym. Chem. Ed., 19, 1901 (1981).

11. G. Chen and R. W. Lenz, J. Polym. Sci., Polym. Chem. Ed., 22, 3189 (1984),

12. C. Ober, J.-I. Jin and R. W. Lenz, Polym. J., 14, 9 (1982).

13. C. K. Ober, T. Bluhm and R. W. Lenz, presented at the International Congress of Pacific Basin Societies, Honolulu, Hawaii, Dec. 1984.

14. M. J. S. Dewar and R. S. Goldberg, J. Org. Chem., 35, 2711 (1970).

15. W. R. Krigbaum, J. Watanabe and T. Ishikawa, Macromolecules, 16, 1271 (1983).

16. A. Roviello and A. Sirigu, Makromol. Chem., 183, 895 (1982).

17. A. Blumstein and 0 . Thomas, Macromolecules, $\frac{15}{15}, 1264$ (1982).

18. A. Abe, Macromolecules, 17, 2280 (1984).

19. P. J. Flory, Adv. Polym. Sci., 59, 2 (1984).

20. P. J. Flory, in Recent Advances in Liquid Crystalline Polymers, L. L. Chapoy, Ed., Elsevier Applied Science Publishers, New York, p. 99 (1985).

21. A. Ten Bosch, P. Maissa and P. Sixou, in Polymeric Liquid Crystals, A. Blumstein, Ed., Plenum Press, New York, p. 109 (1985).

22. D. Y. Yoon, S. Bruckner, W. Volksen, J. C. Scott and A. Griffin, Faraday Discuss. Chem. Soc., 79, (1984) (in press).

23. A. Blumstein, S. Vilasagar, S. Ponrathnam and S. B. Clough, J. Polym. Sci., Polym. Chem. Ed., 20, 877 (1982).

24. Q.-F. Zhou, $\bar{R}$. W. Lenz and J.-I. Jin, Ref. 21, p. 257.

25. G. W. Gray, Liquid Crystals and Plastic Crystals, Vol. 1, Halsted Press, New York, p. $103(1974)$.

26. Q.-F. Zhou and R. W. Lenz, J. Polym. Sci., Polym. Chem. Ed., 21, 3313 (1983).

27. Q.-F. Zhou, J.-I. Jin and R. W. Lenz, Can. J. Chem., 63, $181 \frac{21}{(1985)}$.

28. J. C. Dubois and A. Beguin, Mol. Cryst. Liq. Cryst., $\frac{47}{97}, 193$ (1978).

29. M. J. S. Dewar and A. C. Griffin, J. Am. Chem. Soc., 97,6652 (1975).

30. P. Nieri, to be published.

31. A. Furukawa, to be published.

32. W. J. Jackson, Jr., Macromolecules, 16, 1027 (1983).

33. G. W. Calundann and M. Jaffe, Proc. Robert A. Welch Conf. Chem. Res. XXVI, Houston, Texas, p. 247 (1982). 